\title{
The Correlation Between Landuse Changes WITH ROAD DENSITY In URBAN FrInge SOUTH SURAKARTA
}

\author{
Dewangga Megaloka Putri ${ }^{1}$ \\ URBAN AND REGIONAL PLANNING ENGINEERING \\ ENGINEERING FACULTY \\ Sebelas Maret UniVERSiTy, SURAKarta \\ EMAIL:DEWANGGA.MEGA@GMAIL.COM \\ KUSWANTO NURHADI ${ }^{2}$ \\ URBAN AND REGIONAL PLANNING ENGINEERING \\ ENGINEERING FACULTY \\ SEbelas Maret UniVERSity, SURAKARTA \\ ERMA FITRIA RINI \\ URBAN AND REGIONAL PLANNING ENGINEERING \\ ENGINEERING FACULTY \\ SEBElas MARET UNIVERSITY, SURAKARTA
}

\begin{abstract}
From time to time the poplulation growth effect on the needs-of-lands. The growth of the city affect the changes of the sub-urban in a phisycal and activities. It arises as a result from the need-for-land that already not able to be fullfiled by the city Itself. Eventually, lands in the sub-urban transformed which previously dominated by nonbuilt-up land turn into built-up land. The movements from sub-urban to city also increased. The feeder roads between sub-urban and the city gets more dense. The study aims to review developments on the land use and density of roads in the period of time between 2010 Until 2016 and the correlation between land use development and density of roads. This research is using deductive method and ordinal regression analysis techniques. The datas that be used are primary data obtained through field observation and secondary data through study documents. The result shows the correlation between the land use development and density urban roads in the South urban fringe in the Surakarta city.
\end{abstract}

Keywords: land-use development, roads density

\section{PENDAHULUAN}

Perkembangan pada pusat kota, turut berdampak pada perkembangan di pinggiran kota baik secara segi perkembangan fisik maupun aktivitas. Pada akhirnya, lahan-lahan pinggiran kota bertransformasi dari yang sebelumnya merupakan lahan tak terbangun menjadi lahan terbangun untuk memenuhi supply kebutuhan lahan. Dari waktu ke waktu sejalan dengan meningkatnya jumlah penduduk perkotaan, serta meningkatnya tuntutan kebutuhan akan kehidupan dalam aspek-aspek politik-ekonomi, sosial, budaya dan tekonologi telah mengakibatkan meningkatnya kebutuhan ruang kekotaan yang besar (Yunus:1992). Sama halnya yang dijelaskan oleh (Adisasmita:2011) Semakin sulitnya memperoleh fasilitas perumahan di daerah perkotaan, mendorong sebagian penduduk perkotaan untuk memilih bertempat tinggal di luar perkotaan, setiap pagi menggunakan kendaraan pribadi atau kendaraan umum untuk pergi bekerja di kota, dan setelah jam kerja selesai mereka pulang ke tempat tinggalnya di luar kota.Dalam fakta eksisting yang ada, guna lahan di Kota Surakarta tegolong sedang. Kepadatan penduduk 
rata-rata di Kota Surakarta sebesar 11.582jiwa/Km2 atau 115,82jiwa/Ha dan luas permukiman tahun 2014 sebesar 2.874,93 Ha, jumlah tersebut mengambil porsi $64 \%$ dari total luas Kota Surakarta. Pada sektor ekonomi, guna lahan yang termasuk dalam jenis penggunaan komersil mengambil porsi $15 \%$ dari total luas Kota Surakarta.

Bersamaan dengan fenomena tersebut, lahan-lahan agraris seperti sawah dan perkebunan yang terletak di dekat kota mulai beralih menjadi kawasan permukiman. Pemicu dari fenomena tersebut adalah kota inti atau coreregion sudah tidak mampu menampung penduduk untuk menambah lahan permukiman baru di dalam kota, untuk itu lahan yang potensial untuk tempat bermukim adalah lahan-lahan pertanian di sekitar pinggiran perkotaan. Hal tersebut dapat memicu pergerakan baru yang berasal dari pinggiran kota. Di Kota Surakarta terdapat 4 jalan penghubung dari total 12 ruas jalan yang mengalami kemacetan. $\mathrm{Hal}$ tersebut akan menjadi permasalahn di kemudian hari apabila tidak ada kajian perkiraan mengenai seberapa besar pertumbuhan yang akan terjadi dan seberapa kuat hubungan pertumbuhan guna lahan dengan permasalahn transportasi kota.

Penelitian ini dilakukan untuk mengetahui hubungan perkembangan guna lahan terhadap kepadatan ruasa jalan penghubung di daerah pinggiran. Ruang lingkup penelitian ini adalah kawasan urban fringe sebelah selatan Kota Surakarta dan mengambil kurun waktu pengamatan dari tahun 2010 hingga tahun 2016.

\section{TINJAUAN PUSTAKA}

Wilayah pinggiran kota menurut (Yunus:2000) merupakan wilayah dengan fenomena konversi lahan pedesaan menjadi lahan perkotaan dengan sangat cepat atau ekspansi kota ke wilayah terdekat sekitarnya (Yunus, 2008). Ekspansi kota yang paling dapat dilihat secara jelas yaitu dengan adanya perubahan guna lahan yang semula dominan non terbangun sekarang menjadi berangsur dominan lahan terbangun. Wilayah pinggiran juga dapat di identifikasikan dimana masih banyak penduduk yang mau menglaju untuk b erkegiatan ke kota (Mcgee, 1994 dalam Yunus, 2008). Konversi lahan atau perubahan guna lahan adalah alih fungsi atau mutasi lahan secara umum menyangkut transformasi dalam pengalokasian sumber daya lahan suatu penggunaan ke penggunaan lain (Tjahyati, 1997). Menurut (Sandy, 1960) perubahan penggunaan lahan dapat saja terjadi apabila adanya perubahan/perbedaan nilai fungsi lahan sebelumnya dan sesudahnya yang bernilai ekonomi lebih tinggi dari sebelumnya. Salah satu pendorongnya adalah peningkatan jumlah penduduk dan kegiatan lainnya dapat menimbulkan perubahan dalam penggunaan lahan. Dalam penjelasan (Bourne, 1982) bahwa beberapa faktor yang menjadi penyebab terjadinya penggunaan lahan yaitu : perluasan batas kota, peremajaan di pusat kota, perluasan jaringan infrastruktur terutama jaringan transportasi; serta tumbuh dan hilangnya pemusatan aktifitas tertentu.

Kepadatan jalan dapat diukur melalui seberapa besar derajat kejenuhan jalan tersebut. Derajat kejenuhan berkaitan dengan arus lalu lintas, arus lalu lintas sendiri adalah jumlah kendaraan bermotor yang melewati suatu titik pada jalan persatuan waktu (Manual Kapasitas Jalan Indonesia, 1997). Sedangkan kapasitas arus total arus maksimum suatu titik di jalan yang dapat dipertahankan persatuan jam pada kondisi yang tertentu. Berdasarkan IHCM (Indonesia Highway Capacity Manual) derajat kejenuhan adalah perbandingan antara jumlah arus total dengan kapasitas arus total. 
III. METODE PENELITIAN

Metode penelitian ini berisi ruang lingkup penelitian dan metode analisis yang digunakan untuk mengetahui hubunganperkembangan guna lahan terhadap kepadatan ruas jalan penghubung

A. Ruang Lingkup

Batasan area penelitian ini adalah kawasan pinggiran atau urban fringe seblaah selatan Kota Surakarta yaitu Kecamatan Baki, Grogol dan Kartasura. Jalan yang diamati adalah jalan penghubung dari ketiga kecamatan tersebut menuju Kota Surakarta yaitu Jalan Yos Sudarso, Jalan Brigjend Sudiarto, Jalan Veteran dan Jalan dr. Radjiman. Kurun waktu pengamatan yaitu mulai dari tahun 2010 hingga 2016. B. Metode Analisis

Penelitian untuk mengidentifikasi hubungan perkembangan guna lahan terhadap kepadatan jalan menggunakan pendekatan deduktif, yaitu penelitian yang dimulai dengan mengkaji teori preferensi belanja dan perkembangan pasar guna mendapatkan arahan dalam menentukan kebutuhan data.

Variabel dalam penelitian ini adalah perubahan guna lahan yang digolongkan menjadi 5 jenis yaitu permukiman, perdagangan dan jasa, perkantoran, pendidikan dan industri sebagai variabel bebas dan kepadatan jalan sebagai variabel terikat

Teknik analisis data yang digunakan dalam penelitian ini yaitu:

1. Analisis Deskripsi Eksplanatif

Analisis ini digunakan untuk mengetahui perubahan penggunaan lahan dan kepadatan jalan dengan menggunakan perhitungan kuantitatif. Pada awalnya dilakukan perangkingan untuk mendapatkan kelas yang selanjutnya digunakan untuk menggolongkan perubahan-perubahan yang terjadi. Penggolongan menurut kelas tersebut nantinya akan digunakan untuk analisis selanjutnya.

Tabel 1. Tabel Penilaian Kelas DataPerubahan Penggunaan Lahan

\begin{tabular}{|c|c|c|c|}
\hline Input & Proses & Output & Tolok Ukur \\
\hline $\begin{array}{l}\text { Luas } \\
\text { masing- } \\
\text { masing } \\
\text { jenis } \\
\text { penggunaa } \\
\text { n lahan } \\
\text { pada tahun } \\
2010,2012, \\
2014 \text { dan } \\
2016\end{array}$ & $\begin{array}{l}\text { Menghitun } \\
\text { g besarnya } \\
\text { perubahan } \\
\text { dengan } \\
\text { rumus : } \\
\text { p } \\
\frac{y-x}{x} \cdot 100 \%, \\
\text { dengan } \\
\text { p }= \\
\text { presentase } \\
\text { peningkata } \\
\text { n } \\
y=\text { nilai } \\
\text { pada tahun } \\
\text { berikutnya } \\
\mathrm{x}=\text { nilai } \\
\text { pada tahun } \\
\text { sebelumny } \\
\text { a }\end{array}$ & $\begin{array}{l}\text { Tingkat } \\
\text { perubah } \\
\text { an pada } \\
\text { masing- } \\
\text { masing } \\
\text { jenis } \\
\text { penggu } \\
\text { naan } \\
\text { lahan }\end{array}$ & $\begin{array}{l}\text { - Skala 1 : } \\
\text { sangat } \\
\text { rendah } \\
\text { - Skala } 2 \text { : } \\
\text { rendah } \\
\text { - Skala } 3: \\
\text { sedang } \\
\text { - Skala } 4: \\
\text { tinggi } \\
\text { - Skala } 5: \\
\text { sangat } \\
\text { tinggi } \\
\text { Besaran } \\
\text { presentase } \\
\text { klasifikasi } \\
\text { dihitung } \\
\text { dengan nilai } \\
\text { interval pada } \\
\text { masing- } \\
\text { masing sub } \\
\text { variabel }\end{array}$ \\
\hline
\end{tabular}

Tabel 2. Tabel Penilaian Kelas DataPerubahan Kepadatan Jalan

\begin{tabular}{|c|c|c|c|}
\hline Input & Proses & $\begin{array}{c}\text { Outpu } \\
t\end{array}$ & Tololk Ukur \\
\hline $\begin{array}{l}\text { Derajat } \\
\text { kejenuh } \\
\text { an jalan } \\
\text { pada } \\
2010 \text {, } \\
2012 \text {, } \\
2014 \\
\text { dan } \\
2016\end{array}$ & $\begin{array}{l}\text { Melakukan } \\
\text { penghutungan } \\
\text { dengan data } \\
\text { volume arus } \\
\text { dengan } \\
\text { kapasitas jalan } \\
\text { untuk } \\
\text { memperoleh } \\
\text { derajat } \\
\text { kejenuhan/ke } \\
\text { padatan jalan. } \\
\text { Kemudian dari } \\
\text { hasil } \\
\text { perhitungan } \\
\text { tersebut } \\
\text { dilakukan } \\
\text { penggolongan } \\
\text { berdasarkan } \\
\text { klasifikasi } \\
\text { yang } \\
\text { dikeluarkan } \\
\text { oleh United } \\
\text { States } \\
\text { Highway } \\
\text { Capacity } \\
\text { Manual } \\
\text { (USHCM } \\
\text { l985). }\end{array}$ & $\begin{array}{l}\text { Nilai } \\
\text { kepad } \\
\text { atan } \\
\text { jalan } \\
\text { setiap } \\
\text { tahunn } \\
\text { ya. }\end{array}$ & 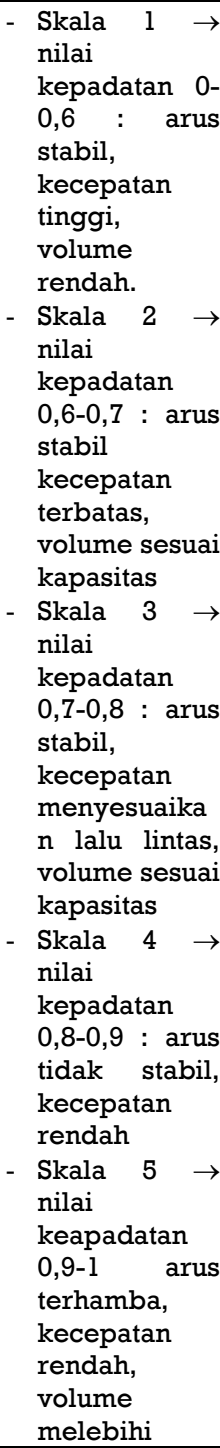 \\
\hline
\end{tabular}


\begin{tabular}{|l|l|l|l|}
\hline & & & kapasitas \\
\hline
\end{tabular}

\section{Analisis Regresi Ordinal}

Regresi Ordinal adalah regresi dengan data ordinal. Apabila biasanya regresi umum menggunakan data skala rasio, maka pada regresi ini peneliti menggunakan data nominal. $\mathrm{Hal}$ tersebut bertujuan untuk memperolaeh hasil regresi meskipun data yang diperoleh tidak memenuhi syarat distribusi normal dan jumlah data kurang dari 30 data.

\section{HASIL DAN PEIMBAHASAN}

Menurut hasil penelitian, terdapat hubungan antara perubahan guna lahan dan kepadatan jalan di urban fringe selatan Kota Surakarta.

A. Perubahan Guna Lahan

Pengembangan permukiman di daerah urban fringe sebelah selatan Kota Surakarta sudah digagas sejak lama sebagai alternatif permukiman Kota Surakarta. Gagasan tersebut muncul pada tahun 1975 oleh salah satu pengembang yaitu PT. Pondok Solo Permai berpandangan bahwa Kota Surakarta mempunyai keterbatasan sumber daya lahan untuk pengembangan permukiman. Gagasan tersebut berujung pada pemilihan kawasan urban fringe sebelah selatan sebagai alternatif permukiman yang mana dalam gagasan itu meliputi Kecamatan Grogol dan Baki, meskipun begitu Kecamatan Kartasura memang telah lama berkembang sebagai kawasan permukiman. Pada setiap kawasan yang mengalami perkembangan tidak akan lepas dari perkembangan guna lahan pada sektor perdagangan juga. Selain dikenal sebagai pusat permukiman baru, wilayah selatan Kota Surakarta juga dikenal sebagai pusat tumbuhnya guna lahan komersil. Berbagai mall, showroom kendaraan bermotor, pertokoan, restoran dan hotel menjamur.
Sebagai wilayah yang mempunyai ciri perkotaan yang kuat, wilayah penelitian mempunyai aktivitas perkantoran yang cukup mengambil porsi dalam keragaman guna lahan. Pada tahun 2010 hingga 2012 tidak terdapat perubahan luasan guna lahan yang cukup berarti, akan tetapi peningkatan antara tahun 2012 hingga 2014 tergolong banyak.Sama halnya dengan perkembangan guna lahan pendidikan dan guna lahan industri.Data tabel dan diagram yang memaparkan mengenai perubahan guna lahan pada kawasan penelitian dapat dilihat dalam tabeltabel dibawah ini.

Tabel 3. Luasan Perubahan Guna Lahan

\begin{tabular}{|c|c|c|c|c|c|c|c|c|}
\hline \multirow{7}{*}{$\begin{array}{c}\text { Jenis } \\
\text { Guna } \\
\text { Laha } \\
\text { n }\end{array}$} & \multicolumn{8}{|c|}{ Tahun } \\
\hline & \multicolumn{2}{|c|}{2010} & \multicolumn{2}{|c|}{2012} & \multicolumn{2}{|c|}{2014} & \multicolumn{2}{|c|}{2016} \\
\hline & $\mathrm{Lu}$ & $\operatorname{Pr}$ & $\mathrm{Lu}$ & $\operatorname{Pr}$ & $\mathrm{Lu}$ & $\operatorname{Pr}$ & $\mathrm{Lu}$ & $\mathrm{Pr}$ \\
\hline & as & os & as & os & as & os & as & os \\
\hline & $(\mathrm{k}$ & ent & $(\mathrm{k}$ & ent & $(\mathrm{k}$ & ent & $(\mathrm{k}$ & ent \\
\hline & $\mathrm{m} 2$ & as & $\mathrm{m} 2$ & as & $\mathrm{m} 2$ & as & $\mathrm{m} 2$ & as \\
\hline & ) & $\mathrm{e}$ & ) & $\mathrm{e}$ & ) & $\mathrm{e}$ & ) & $\mathrm{e}$ \\
\hline & 17 , & 41 & 14, & 34 & 11 , & 26 & & 22 \\
\hline RTH & 8 & $\%$ & 8 & $\%$ & 3 & $\%$ & 9,6 & $\%$ \\
\hline Perd & & & & & & & & \\
\hline $\begin{array}{l}\text { agan } \\
\text { gan }\end{array}$ & & & & & & 14 & & 16 \\
\hline Jasa & 2,6 & $6 \%$ & 3,9 & $9 \%$ & 6,1 & $\%$ & 6,9 & $\%$ \\
\hline Pend & & & & & & & & \\
\hline $\begin{array}{l}\text { ldika } \\
\text { n }\end{array}$ & 0,9 & $2 \%$ & 0,9 & $2 \%$ & 1,3 & $3 \%$ & 1,3 & $3 \%$ \\
\hline Indu & & & & 10 & & 10 & & 11 \\
\hline stri & 3,9 & $9 \%$ & 4,3 & $\%$ & 4,3 & $\%$ & 4,8 & $\%$ \\
\hline Perk & & & & & & & & \\
\hline $\begin{array}{l}\text { antor } \\
\text { an }\end{array}$ & 0,4 & $1 \%$ & 0,4 & $1 \%$ & 0,9 & $2 \%$ & 0,9 & $2 \%$ \\
\hline Perm & & & & & & & & \\
\hline ukim & 17, & 41 & 19 , & 44 & 19, & 45 & 20 , & 46 \\
\hline & 8 & $\%$ & 1 & $\%$ & 5 & $\%$ & 0 & $\%$ \\
\hline
\end{tabular}

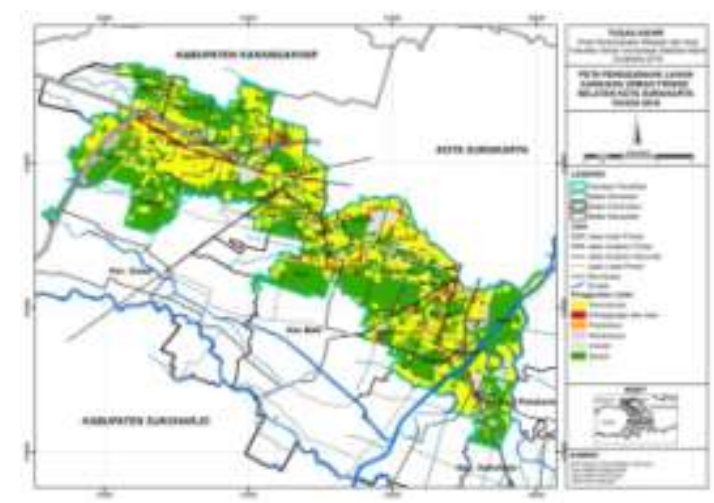


Gambar 1.Peta Luasan Perubahan Guna Lahan Tahun 2010

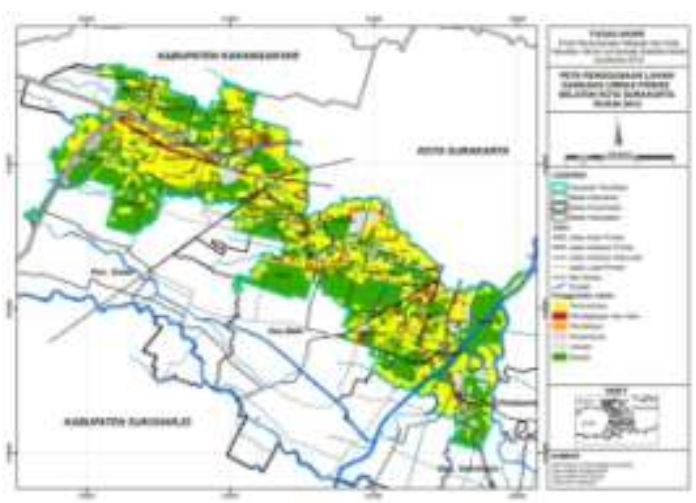

Gambar 2.Peta Luasan Perubahan Guna Lahan Tahun 2012

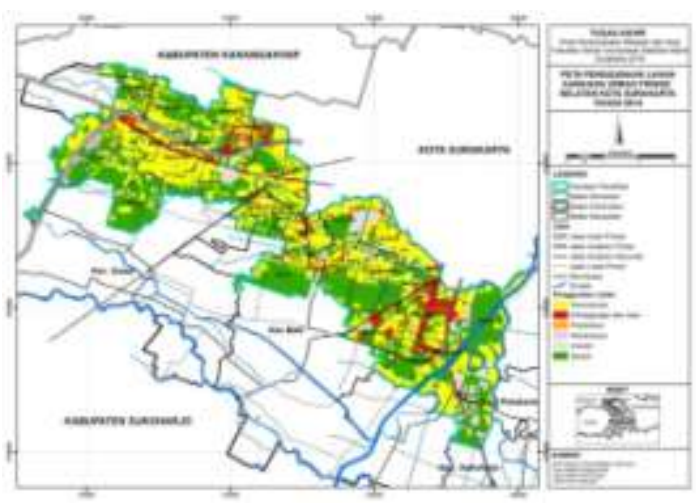

Gambar 3. Peta Luasan Perubahan Guna Lahan Tahun 2014

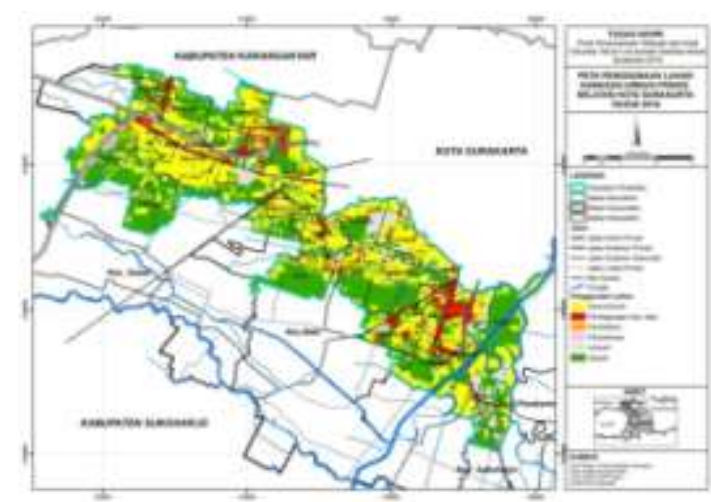

Gambar 4. Peta Luasan Perubahan Guna Lahan Tahun 2016

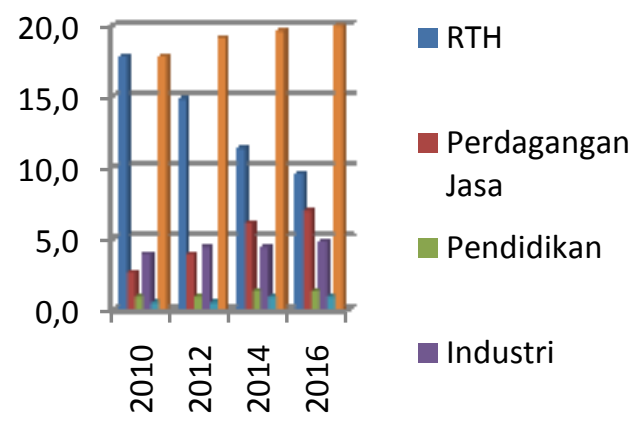

Gambar 5. Grafik Luasan Perubahan Guna Lahan

B. Kepadatan Ruas Jalan

Pada penelitian ini terdapat 4 jalan yang menjadi fokus utama yaitu jalan-jalan yang menghubungkan antara wilayah urban fringe dengan Kota Surakarta. Jalan-jalan tersebut antara lain Jalan Dr. Radjiman, Jalan Brigjend. Sudiarto, Jalan Yos Sudarso dan Jalan Veteran. Seluruh jalan tersebut merupakan jalan dengan fungsi kolektor.

Kondisi lalu lintas pada Jalan Yos Sudarso cenderung baik dari tahun ke tahun. Pada tahun 2010 VCR mencapai angka 0,7 dimana angka tersebut hampir mendekati angka krisis (macet), kemudian menurun secara teratur dari tahun 2012 hingga 2014. Hal tersebut dipengaruhi oleh penurunan volume lalu lintas yang melewati ruas jalan tersebut. Hal tersebut dapat dimungkinkan akibat tersedianya perubahan perilaku pelaku perjalanan yang mengambil rute yang berbeda. Titik kemaetan biasanya terjadi di sebelum jembatan perbatasan dan sesudahnya, di sepanjang kawasan retail sebelum pintu masuk ke kawasan The Park dan sepanjang kawasan retail nonongan. Nilai VCR yang tinggi terjadi di beberapa ruas, akan tetapi tidak semua titik ruas Jalan Yos Sudarso mempunyai VCR yang tinggi sehingga VCR rata-rata dari Jalan Yos Sudarso tergolong sedang.

Kondisi lalu lintas dijalan Brigjend Sudiarto tegolong naik-turun dari tahun ke tahun. Pada tahun 2010 VCR berada pada angka 0,62 dimana masih tergolong sedang, kemudian pada thun 
2012 naik menjadi 0,7. Pada tahun 2012 VCR Jalan Brigjend Sudiarto tergolonghampir memasuki angka kritis. Pada tahun 2014 angka VCR tergolong tinggi pada angka 0,75, kemudian menurun di tahun 2016 kembali di angka 0,6.

Kondisi lalu lintas di Jalan Radjiman tergolong padat. Pada tahun 2010 angka VCR mencapai angka 1 dimana pada angka tersebut tergolong pada status krisis, artinya pada ruas jalan tersebut serin terjadi kemacetan. Pada tahun 2012 angka VCR menurun hingga angka 0,73 . Dari tahunke tahun terjadi penurunan kapasitas jalan, hal ini dapat terjadi akibat perubahan pembagian arah lalu lintas, hambatan samping jalan yang semakin meningkat seperti on street parking yang semakin banyak atau pembangunan pembatas jalan.

Kondisi lalu lintas jalan veteran terhitung konstan dari tahun ke tahun. Angka VCR selalu berapa pada rentang $0-0,6$ hingga 0,7 . Jalan ini termasuk jalan yang sibuk

karena banyak kawasan perdagangan dan jasa yang ada di jalan akan tetapi volume lalu lintas stabil dan tidak termasuk dalam golongan ruas yang macet. Data tabel dan diagram yang memaparkan mengenai perubahan guna lahan pada kawasan penelitian dapat dilihat dalam Lampiran 3.

C. Analisa Hubungan Perubahan Guna LahanTerhadap Kepadatan Jalan.

Dalam analisis ini variabel terikat yaitu kepadatan jalan satu-satu dianalisis dengan seluruh variabel bebas yaitu variabel perubahan guna lahan, jadi akan ada 4 hasil analisis. Hal tersebut dikarenakan jalan yang dianalisis merupakan jalan kolektor jadi akan ada kemungkinan bahwa kegiatan di seluruh wilayah penelitian menggunakan ke empat jalan tersebut. Sebelum dilakukan analisis, data lebih dulu diubah dari data rasio menjadi data ordinal atau jenjang.

Tabel 4. Perubahan Guna Lahan

\begin{tabular}{|l|l|l|l|l|l|l|}
\hline $\begin{array}{l}\text { Jenis } \\
\text { Guna } \\
\text { Lahan }\end{array}$ & $\begin{array}{l}\mathbf{2 0 1 0} \\
\mathbf{2 0 1 2}\end{array}$ & $\begin{array}{l}\text { Or } \\
\text { do }\end{array}$ & $\begin{array}{l}\mathbf{2 0 1 2 -} \\
\mathbf{2 0 1 4}\end{array}$ & $\begin{array}{l}\text { Or } \\
\text { do }\end{array}$ & $\begin{array}{l}\mathbf{2 0 1 4} \\
\mathbf{2 0 1 6}\end{array}$ & $\begin{array}{l}\text { Or } \\
\text { do }\end{array}$ \\
\hline $\begin{array}{l}\text { Perdagan } \\
\text { gan Jasa }\end{array}$ & 50,0 & 3 & 55,6 & 3 & 14,3 & 1 \\
\hline $\begin{array}{l}\text { Pendidika } \\
\text { n }\end{array}$ & 0,0 & 1 & 50,0 & 3 & 0,0 & 1 \\
\hline Industri & 11,1 & 1 & 0,0 & 1 & 10,0 & 1 \\
\hline $\begin{array}{l}\text { Perkantor } \\
\text { an }\end{array}$ & 0,0 & 1 & 100,0 & 5 & 0,0 & 1 \\
\hline $\begin{array}{l}\text { Permukim } \\
\text { an }\end{array}$ & 7,3 & 1 & 2,3 & 1 & 2,2 & 1 \\
\hline
\end{tabular}

Tabel 5. Perubahan Kepadatan Jalan

\begin{tabular}{|l|c|l|c|c|c|c|}
\hline \multicolumn{1}{|c|}{ Jalan } & $\begin{array}{c}\mathbf{2 0 1} \\
\mathbf{2}\end{array}$ & $\begin{array}{c}\text { Ord } \\
\mathbf{0}\end{array}$ & $\begin{array}{c}\mathbf{2 0 1} \\
\mathbf{4}\end{array}$ & $\begin{array}{c}\text { Ord } \\
\mathbf{0}\end{array}$ & $\begin{array}{c}\mathbf{2 0 1} \\
\mathbf{6}\end{array}$ & $\begin{array}{c}\text { Ord } \\
\mathbf{0}\end{array}$ \\
\hline $\begin{array}{l}\text { Yos } \\
\text { Sudarso }\end{array}$ & 0,59 & 1 & 0,46 & 1 & 0,42 & 1 \\
\hline Sudiarto & 0,68 & 2 & 0,74 & 2 & 0,56 & 1 \\
\hline $\begin{array}{l}\text { dr. } \\
\text { Radjiman }\end{array}$ & 0,69 & 2 & 0,95 & 6 & 0,74 & 2 \\
\hline Veteran & 0,70 & 2 & 0,60 & 1 & 0,72 & 2 \\
\hline
\end{tabular}

Pada analisis ini tahap pertama adalah melakukan intepretasi terlebih dahulu, yaitu menentukan dugaan pada data yang dianalisis. Ho = Perubahan guna lahan tidak berhubungan terhadap kepadatan jalan, $\mathrm{Hl}=$ Perubahan guna lahan terhadap kepadatan jaringan jalan. Berdasarkan tabel model fitting information(Tabel dapat dilihat pada Lampiran 5) diketahui bahwa p-value masing-masing untuk setiap jalan adalah
a. Jalan dr. Radjiman $=0.037$
b. Jalan Brigjend Sudiarto $=0.037$
c. Jalan Yos Sudarso $=0.143$
d. Jalan Veteran $=0.143$
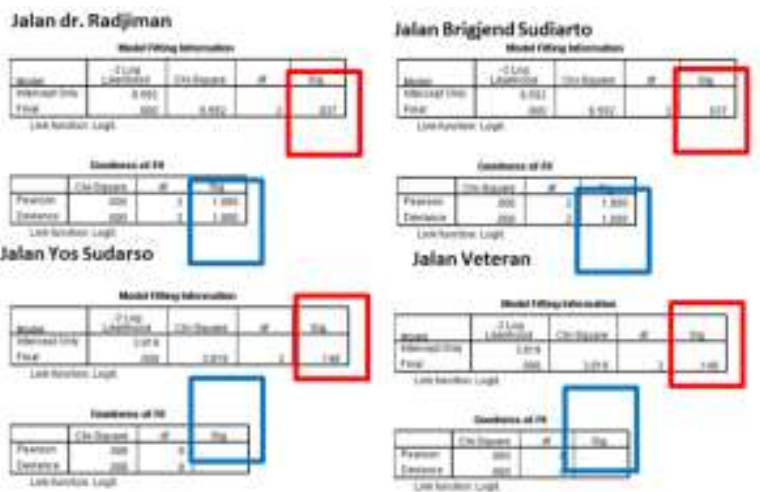
Gambar6. Gambar Hasil Analisis SPSS

Apabila p-value < 0.05, maka Ho ditolak dan $\mathrm{Hl}$ diterima. Dalam analisis tersebut terdapat 2 jalan dengan $p$-value $<0.05$ yaitu Jalan Brigjend Sudiarto dengan Jalan dr. Radjiman dan 2 jalan dengan $\mathrm{p}-$ value $>0.05$ yaitu Jalan Veteran dengan Jalan Yos Sudarso. Maka kesimpulannya, Ho ditolak untuk kasus Jalan Brigjend Sudiarto dan Jalan dr. Radjiman dan Ho diterima pada Jalan Yos Sudarso dan Jalan Veteran. Dengan kata lain, perubahan guna lahan pada area Urban Fringe Selatan Kota Surakarta berhubungan dengan kepadatan jaringan jalan pada dua jalan yaitu Jalan Brigjend Sudiarto dan Jalan dr. Radjiman.

\section{REFERENSI}

Bourne, L.S., ed. 1982. Internal Structure of the City: Readings on Urban Form, Growth, and Policy, 2nd edition. Oxford: Oxford University Press.

Sandy, I Made. 1977. Tata Guna Lahan Perkotaan dan Pedesaan. Jakarta: Penerbit Bharata Anindya

Yunus, Hadi Sabari. 2008. Dinamika Wilayah Peri-Urban: Determinasi Masa Depan Kota. Yogyakarta: Pustaka Pelajar.

Dirjen Bina Marga, Dep. PU Indonesia. 1997. Manual Kapasitas Jlaan (MKJI). Jakarta. PT. Bina Karya (Persero. 